\title{
Diálogos entre as produções acadêmico-científicas da Educação Física e os documentos orientadores da Educação Infantil
}

https://doi.org/10.11606/issn.1981-4690.v35i1p67-79
Rodrigo Lema Del Rio Martins*

Luísa Helmer Trindade** André da Silva Mello*

\section{Resumo}

Analisa as produções acadêmico-científicas da Educação Física sobre a Educação Infantil, em diálogo com as concepções e pressupostos presentes nos atuais documentos orientadores dessa etapa de ensino no Brasil. Realiza um Estado da Arte sobre essas publicações, buscando inventariar e sistematizar a produção dessa área do conhecimento. Trata-se de uma pesquisa bibliográfica que utiliza como fontes: 76 teses e dissertações defendidas nos Programas de Pós-Graduação em Educação Física do Brasil 117 artigos veiculados em revistas científicas da área e 25 trabalhos acadêmicos publicados nos Anais do Congresso Brasileiro de Ciências do Esporte. Adota o software Iramuteq para análise do corpus textual. Constata-se que, embora timidamente, aparecem referenciais teóricos mais alinhados com a perspectiva de infância presente nos documentos orientadores da Educação Infantil no País. Predominam nas produções investigadas concepções biologicistas de Educação Física infantil e de criança sob forte influência de referenciais teóricos provenientes do campo Psicologia e do Comportamento Motor, divergindo, assim, do que preconizam os referidos documentos.

Palavras-chave: Publicações; Estado da arte; Documentos legais e pedagógicos; Infância.

\section{Introdução}

A Educação Infantil, tal como a conhecemos atualmente, é fruto de um processo histórico de transformaçóes que a acompanhou desde o seu surgimento, entre o fim do século XIX e o início do século XX. As primeiras creches criadas no Brasil estavam ligadas ao trabalho filantrópico de instituiçôes religiosas com a intençâo bem definida de criar espaços formais de atendimento assistencial às mulheres que ingressavam no mercado de trabalho.

$\mathrm{Na}$ década de 1980, com os dos intensos debates acerca da Constituiçáo Federal, observamos um grande avanço no estabelecimento da Educação Infantil como direito social, pois é a partir dela que foi assegurada a responsabilização do Estado com o atendimento às crianças em instituiçóes escolares para não mais apenas serem "cuidadas", mas, também, "educadas". Esse fato gerou como consequência a migração das creches da esfera das Secretarias de
Assistência Social para as Secretarias de Educação. Contudo, como destaca Kunlman JR ${ }^{1}$ essa migração não significou necessariamente a superação da concepçáo assistencialista que marca historicamente a Educação Infantil.

Com o advento do Estatuto da Criança e do Adolescente ${ }^{2}$, em 1990, por meio da Lei no 8.069/90, as crianças săo, de fato, inseridas no mundo dos direitos sociais. Isso porque

\footnotetext{
A criança e o adolescente gozam de todos os direitos fundamentais inerentes à pessoa humana, sem prejuízo da proteção integral de que trata esta Lei, assegurando-lhes, por lei ou por outros meios, todas as oportunidades de facilidades, a fim de lhes facultar o desenvolvimento físico, mental, moral, espiritual e social, em condiçôes de liberdade e dignidade (Art. $3^{\circ}$ ).
}

* N ú c l e o d e Aprendizagens com as Infâncias e seus Fazeres, Universidade Federal Rural do Rio de Janeiro, Rio de Janeiro, RJ, Brasil.

* * N ú c l e o d e Aprendizagens com as Infâncias e seus Fazeres, Universidade Federal do Espírito Santo, Vitória, ES, Brasil. 
Concordamos com a leitura de RossettiFerreira ${ }^{3}$ que afirma que esse Estatuto "Serviu ainda como base para a construção de uma nova forma de olhar a criança: uma criança com direito a ser criança”. De certo modo, a Lei no 8.069/90 é um parâmetro utilizado até hoje para guiar as políticas públicas desencadeadas após a sua promulgaçáo. Exemplo disso é a própria Lei de Diretrizes e Bases da Educaçáo Nacional (LDB $)^{4}$ que a toma como balizador juntamente com a Constituição Federal de 1988.

A LDB, de 1996, reconhece a Educação Infantil como primeira etapa da Educação Básica e define que sua a finalidade é promover o desenvolvimento integral da criança até seis anos de idade a complementando a ação da família e da comunidade ${ }^{4}$. PaschoAl e MACHADO $^{5}$ avaliam esse fato como um grande avanço no que diz respeito aos direitos da criança pequena, pois, embora a Educação Infantil não figurasse como obrigatória à época, passa a ser um direito da criança e tem o objetivo de proporcionar condiçóes adequadas para o bem-estar infantil e para o desenvolvimento físico, motor, emocional, social e intelectual da criança, além da ampliaçẫo de suas experiências.

No cenário atual, MarTins ${ }^{6}$ compreende que a Educação Infantil vem passando por um processo de expansão e consolidação no Brasil que é decorrente, entre outras situaçóes, da Emenda Constitucional $\mathrm{n}^{\circ} 59 / 2009$, que tornou obrigatória a matrícula e a frequência de crianças de quatro e cincos anos de idade em instituiçóes formais de ensino em todo o território nacional. Somando-se a isso, temos a aprovação do Plano Nacional de Educação que fixou, como meta a ser atingida, até 2016, a universalização da pré-escola e a ampliação em $50 \%$ da oferta de vagas em creches para crianças até três anos de idade ${ }^{7}$.

Esses processos de expansão e institucionalização da primeira etapa da Educação Básica vêm acompanhados de preocupaçóes pedagógicas acerca da organização e operacionalização do trabalho educativo com as crianças. Várias iniciativas governamentais e de instituiçôes implicadas com a Educação Infantil têm sido empreendidas no sentido de construir orientaçóes legais e pedagógicas de alcance nacional para essa primeira etapa da Educaçáo Básica, com destaque, o Referencial Curricular Nacional para a Educaçáo Infantil $(\mathrm{RCNEI})^{8}$, as Diretrizes Curriculares Nacionais para a Educação Infantil (DCNEIs) ${ }^{9}$ e a Base Nacional Comum Curricular $(\mathrm{BNCC})^{10}$.

Esses documentos legais/pedagógicos constituem parte do esforço em reunir o que vem sendo produzido na área acadêmica e de sistematização das conquistas provenientes dos diferentes campos e sujeitos que integram a Educação Infantil. Todos eles assumem, como função precípua, balizar o trabalho pedagógico desenvolvido pelas instituições públicas e privadas dedicadas a cuidar de crianças pequenas e educá-las.

Nos três referidos documentos, a Educação Infantil é descrita como uma etapa da Educaçáo Básica que não se organiza de maneira disciplinar, ou seja, caracteriza-se por promover processos de ensino-aprendizagem integrados, sem a divisão por disciplinas curriculares e por professores especialistas em cada área do conhecimento, como ocorre nos ensinos Fundamental e Médio.

O trabalho pedagógico desenvolvido nas instituiçóes dedicadas a cuidar e educar de crianças de zero a cinco anos de idade no País toma como referências DCNEIs ${ }^{9}$ e a BNCC $^{10}$. Nesses documentos, é possível perceber, embora não assumidos explicitamente, indícios de diálogos com a Sociologia da Infância ${ }^{11-13}$.

A concepçáo de criança defendida por esse campo do conhecimento assume as crianças sendo atores sociais com participação ativa em seus processos educativos, os quais se dão por meio das negociaçóes que elas realizam com as pessoas adultas e com seus pares, com as quais convivem. Essa perspectiva coaduna com a dos pesquisadores que vêm se preocupando em

$$
\begin{aligned}
& \text { [...] (des)construir a universalidade do conceito de infância, } \\
& \text { tentando ultrapassar leituras meramente reducionistas que } \\
& \text { apenas enxergam a infância como um tempo de passagem } \\
& \text { para a vida adulta, como um ser passivo que acaba por ver } \\
& \text { a educaçáo infantil também como simples preparaçáo para } \\
& \text { a escolarizaçáo } \left.{ }^{14} \text { (p. } 78\right) \text {. }
\end{aligned}
$$

Em ambos os documentos, estáo preconizados pressupostos e concepçóes que precisam ser considerados para se pensar a mediação pedagógica das diferentes áreas do conhecimento, não pelo simples fato de estarem presentes nesses documentos legais/pedagógicos, mas porque neles as crianças são percebidas como sujeitos ativos dos processos de ensino-aprendizagem desenvolvidos na primeira etapa da Educação Básica. As interaçōes e as práticas cotidianas são elementos valorizados para a construção dos significados, das identidades e na produção/apropriação de saberes e de cultura.

Em que pesem as diversas críticas em relaçáo à BNCC $^{10}$, concordamos que a construção da "Base" 
merecia maior diálogo com a sociedade civil e que, em alguns aspectos, ela retrocedeu em sua terceira versão, quando comparada com a primeira e a segunda, mas, ainda assim, compreendemos que, no tocante à Educação Infantil, ela reafirma muitos dos princípios dos quais partilhamos, ao reforçar o entendimento de criança como sujeito de direitos, produtora de cultura e protagonista dos seus processos de socialização. Por essa razão, sem desconsiderar a legitimidade e importância das críticas, servimo-nos da BNCC10 para que, ao lado das DCNEIs ${ }^{9}$, embasem nossa discussão neste artigo.

Temos como hipótese que a presença da Educação Física na Educação Infantil em si não representa, necessariamente, um processo de escolarização e que ela só se sustenta por meio de práticas pedagógicas que tomem como base pressupostos que vêm sendo apontados por parte da produção acadêmica e que, em certo grau, são assumidos pelos documentos orientadores mais recentes $^{9-10}$.

Dada a centralidade do corpo/movimento e dos jogos/brincadeiras nos processos pedagógicos desenvolvidos no âmbito da Educação Infantil, presentes em ambos os documentos, Mello, Zandomínegue, Barbosa et al. ${ }^{15}$ entendem que a Educação Física vem se consolidando na primeira etapa da Educação Básica, favorecendo, assim, a inserção de professores com formação específica nessa área de conhecimento.

A ampliação da presença do professor de Educação Física atuando na Educação Infantil vem impactando diretamente a produção do conhecimento com um aumento expressivo de estudos que tratam da intervenção pedagógica da Educação Física nessa etapa da Educação Básica em periódicos da área Mello et al. ${ }^{16}$.

Essa ampliação do interesse por parte da academia pode ser verificada em diversos trabalhos. Artigo de Moura, Costa e Antunes ${ }^{17}$ analisou seis periódicos nacionais da Educação Física entre os anos de 2000 e 2012, localizando 25 publicações sobre Educação Infantil. No livro "Educação Física na educação infantil: práticas pedagógicas e cotidiano escolar", Mello et al. ${ }^{16}$ encontraram 53 artigos que foram publicados em cinco importantes periódicos dessa mesma área de conhecimento no período de 1979 a 2010 . Ampliando esse período analisado para dezembro de 2014 e para as seis revistas científicas da Educação Física com melhor classificação no WebQualis/Periódicos da Capes, Martins ${ }^{6}$, em sua dissertação, encontrou 74 artigos publicados.
O interesse por compreender a produção acadêmico-científica sobre Educação Infantil também pode ser acompanhado na dissertação de PiCElli ${ }^{18}$, que mapeou todas as teses/dissertaçôes sobre essa temática publicadas por Programas de Pós-Graduação em Educação Física, encontrando 31 no intertíscio de 1977 e 2000 . Já BezerRA ${ }^{19}$ buscou revelar as concepçóes e práticas corporais referentes à Educação Infantil publicadas na Revista de Educação Física do Exército $^{\mathrm{b}}$ entre os anos de 1932 e 1942.

As pesquisas encontradas referentes ao tema versam sobre a produção acadêmico-científica publicada em diferentes veículos de comunicação científica (livros, dissertaçóes e artigos), porém no formato de Estado do Conhecimento ${ }^{\text {c, }}{ }^{20}$. Contudo, não localizamos estudos que tenham dedicado esforços no sentido de produzir uma análise mais alargada dessa produção, conjugando diferentes veículos de comunicação científica, ou seja, elaborando um Estado da Arte ${ }^{21}$. No caso específico desta pesquisa, referimo-nos às teses e dissertaçóes, trabalhos acadêmicos publicados em anais de congresso e artigos científicos.

Os estudos do tipo Estado da $\operatorname{Arte}^{21}$ são importantes para avaliarmos o movimento de uma temática dentro do campo científico. Nesse sentido, as diferentes formas de abordar um objeto evidenciam a pluralidade de enfoques que é pensada pelos pesquisadores, mediante seus interesses e referenciais teóricos utilizados para analisar os dados ${ }^{21}$. No caso específico desta pesquisa, interessa-nos compreender como a produção acadêmico-científica da Educação Física aborda a Educação Infantil, convergindo ou divergindo com uma concepção de infância que compreende a criança como sujeito de direitos, protagonista e produtora de cultura. Esses pressupostos estão ancorados na Sociologia da Infância ${ }^{11-13}$ e, de forma implícita, fundamentam os documentos pedagógicos mais atuais que orientam as práticas educativas na primeira etapa da Educação Básica ${ }^{9-10}$.

O objetivo deste artigo é analisar, em diálogo com as concepçóes e pressupostos presentes nos documentos orientadores da Educação Infantil no Brasil, as produções acadêmico-científicas da Educação Física que abordam a primeira etapa da Educação Básica. Para tanto, realizamos um Estado da Arte ${ }^{21}$ sobre essas produçóes, buscando inventariar e sistematizar a produção dessa área do conhecimento em diálogo com as DCNEIs ${ }^{9}$ e com a BNCC ${ }^{10}$. 


\section{Método}

O delineamento metodológico desta pesquisa é de caráter bibliográfico que, segundo Lima e Міото $^{22}$,

[...] possibilita um amplo alcance de informações, além de permitir a utilização de dados dispersos em inúmeras publicações, auxiliando também na construção, ou na melhor definiçấo do quadro conceitual que envolve o objeto de estudo proposto (p. 40).

Para a realização desta pesquisa, utilizamos as seguintes fontes na produção dos dados: teses e dissertaçóes produzidas nos programas de PósGraduação em Educação Física do Brasil, artigos publicados em revistas científicas da área e trabalhos acadêmicos veiculados nos Anais do Congresso Brasileiro de Ciências do Esporte.

No processo de levantamento dos dados, recorremos ao Banco de Teses e Dissertaçóes da Capes ${ }^{\mathrm{d}}$ para identificar as produçóes que abordaram a Educação Infantil como objeto de estudo.

Os artigos científicos foram pesquisados nos sites oficiais dos seguintes periódicos científicos da Educação Física brasileira: Movimento, Motriz, Motrivivência, Pensar a Prática, Revista Brasileira (RBCE) de Educaçáo Física e Esporte (RBEFE), Revista Brasileira de Ciências do Esporte e Revista de Educação Física da UEM. Esses periódicos foram selecionados de acordo com a sua classificação no Webqualis da Capes (2013-2016), delimitando o nosso corpus de análise aos que estão ranqueados nos estratos superiores: A2, B1 e B2. A opçáo pelos estratos superiores se deve à presunção de que, devido aos rigorosos processos de seleção, nesses periódicos científicos, circulam o que há de mais avançado no campo da Educação Física brasileira ${ }^{6}$.

\section{Resultados}

O primeiro levantamento localizou 184 artigos científicos nas revistas pesquisadas, 31 trabalhos acadêmicos no Conbrace e 99 teses/dissertaçóes provenientes dos Programas de Pós-Graduação em Educaçáo Física do País. Como o foco da nossa investigação recai sobre produçôes nacionais que problematizam a presença da Educação Física na Educação Infantil, excluímos as publicações que não tinham os seus arquivos disponíveis nos
Em relação aos trabalhos acadêmicos, escolhemos o Congresso Brasileiro de Ciências do Esporte (Conbrace) por ele se constituir como um dos principais eventos científicos da Educação Física no Brasil. Desde a sua primeira edição, em 1979, esse evento reúne bianualmente pesquisadores, docentes e estudantes das universidades e dos programas de pós-graduação, como também professores da Educação Básica. Serão consideradas todas as comunicaçóes orais provenientes do Grupo de Trabalho Temático (GTT) "Escola"f nos anais das ediçóes do Conbrace entre 1997 (data de fundação do GTT) e 2015 (último encontro realizado).

A seleção das publicaçóes que interessava a esta pesquisa ocorreu, inicialmente, com base nos seguintes critérios: leitura dos títulos, palavras-chave e resumos nesses três veículos de comunicação científica. Quando não se mostravam suficientes para esclarecer a pertinência da publicação aos critérios estabelecidos, partíamos para a leitura na íntegra do texto.

Em um primeiro momento, este artigo apresenta um panorama sobre o material levantado por meio de indicadores bibliométricos ${ }^{21}$, que se constituem uma técnica quantitativa e estatística. Este trabalho permitiu medir a produção do conhecimento, apontando o seu fluxo temporal e a distribuição nos três veículos de comunicação científica elencados. Na sequência, adotamos o software Iramuteq ${ }^{g}$ que realiza análises sobre corpus textuais, sendo possível examinar textos, entrevistas, documentos, redaçóes etc. para sistematizar os dados encontrados ${ }^{23}$ e, por fim, analisamos os referenciais teóricos de todas as publicaçóes, relacionando-os com os pressupostos presentes nas DCNEIs ${ }^{9}$ e na BNCC ${ }^{10}$.

bancos de dados consultados; aquelas assinadas por autores estrangeiros; as que não traziam a especificidade da Educação Infantil como etapa formal de ensino, mesmo quando se tratava de crianças da faixa etária de zero a cinco anos de idade. Assim, retiramos estudos que foram realizados em instituições de assistência social, de atendimento educacional especializado, projetos de extensão universitária, laboratórios de pesquisa 
ou ambientes domésticos. Após aplicarmos esses critérios, restaram 117 artigos científicos, 76 teses/ dissertações e 25 trabalhos acadêmicos, totalizando 218 publicaçóes.

\section{Análise exploratória dos dados}

O recorte temporal deste estudo compreende o ano de 1980, primeira publicação veiculada, e o ano de 2016, quando finalizamos a coleta de dados. Para melhor identificar como a produção, nesses três veículos de comunicação científica, se estabeleceu nesse período, organizamos os dados na FIGURA 1, que relaciona a quantidade de trabalhos acadêmico-científicos sobre Educação Infantil, e o ano em que foram publicados ao longo do período temporal analisado.
A FIGURA 1 apresenta as 218 publicaçóes distribuídas nos 37 anos que compreendem o nosso recorte temporal, perfazendo uma média de 5,7 publicaçóes por ano. A partir de 1993, essa produção é ininterrupta. Contudo, a produção acadêmico-científica anterior ao ano de 1996 é incipiente, na medida em que apenas quatro artigos científicos e doze teses/dissertaçóes foram publicados. A expansão observada a partir de referido ano deve-se, em parte, à criação do GTT "Escola" em 1997, ano em que são publicados os quatro primeiros trabalhos acadêmicos sobre Educação Infantil no Conbrace. Em relação à linha vermelha do gráfico, que representa esses trabalhos, é preciso ressaltar que esse Congresso, por ser bianual, nos anos pares, a produção acadêmicocientífica relativa a ele sempre é igual a zero.

FIGURA 1 - Fluxo temporal das publicações nos três veículos de comunicação científica.

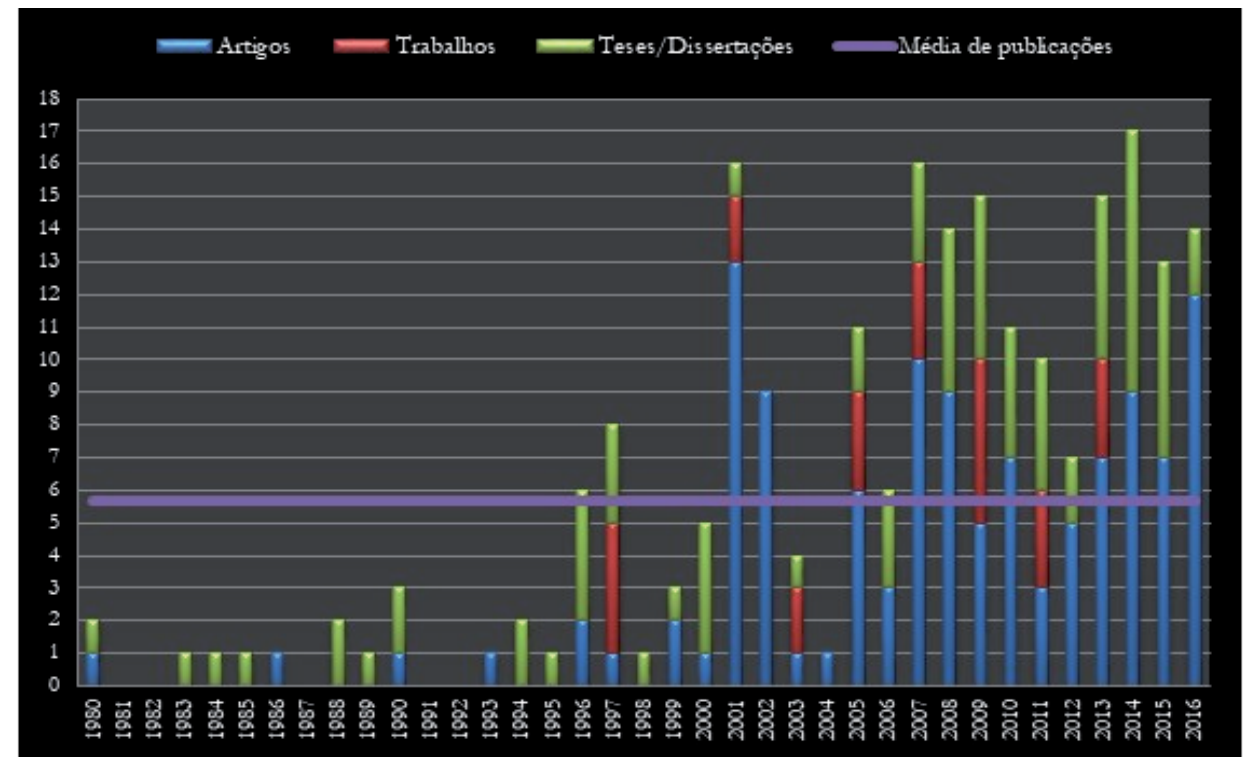

É na primeira década do novo milênio que essa produção se torna consolidada, ao passo que, fora 2003 e 2004, em todos os outros anos a produção acadêmico-científica sobre Educação Infantil está acima da média anual $(5,7)$.

$\mathrm{O}$ ano inaugural da expansão da produção acadêmico-científica coincide com a promulgação da LDB que apresentou uma nova regulamentação para o setor educacional do País. Destacamos o fato de a Educação Infantil ser assumida, pela primeira vez, como uma etapa formal de ensino que compóe a denominada Educação Básica (Educação Infantil,
Ensino Fundamental e Ensino Médio).

\section{Análise qualitativa das publicações}

Após apresentar panoramicamente como a produção acadêmico-científica que relaciona a Educação Física com a Educação Infantil se configurou no período estudado, passamos a analisar mais detidamente as publicaçóes. Optamos por fazer isso por meio dos títulos que, em nossa compreensão, oferecem uma boa medida da síntese do que trata a publicação científica e dos referenciais teóricos 
predominantes por expressarem as concepçóes teóricas e epistemológicas contidas nessas produçóes.

A FIGURA 2, a seguir, organiza as palavras dos títulos de todas as 218 publicaçóes por meio da nuvem de palavras:

A nuvem de palavras tem como função reunir as palavras mais recorrentes no corpus selecionado e agrupá-las de modo que aquelas que tenham maior frequência ocupem o centro da nuvem em tamanho maior que as demais e, consequentemente, as de menor frequência fiquem mais próximas das bordas e diminutas. No caso da FIGURA 2, Educação Física e Educação Infantil se destacam pelo fato de se tratar, justamente, dos temas centrais das produçóes escolhidas para esta pesquisa. Palavras como criança, predeterminado, escolar e professor aparecem secundariamente, próximas ao centro e em tamanho um pouco menor. Ainda menores e mais afastadas do centro, percebemos palavras como brincar, movimento, corpo, infância, desenvolvimento, contexto, prático, gênero, creche, análise, entre outras.

FIGURA 2 - Nuvem de palavras dos títulos das produções acadêmico-científicas.

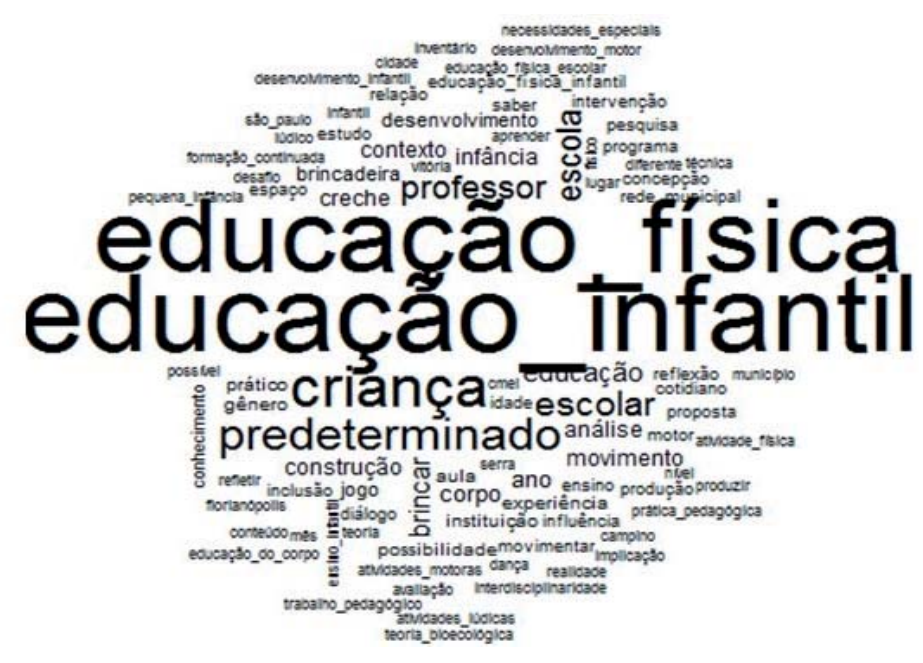

Optamos por avançar para a análise de similitudes, buscando identificar a conexidade que essas palavras possuem entre si, conforme disposto na FIGURA 3. A FIGURA 3 demonstra "três núcleos" (Educação Física, Educação Infantil e Criança) que agrupam uma série de palavras com conexóes entre si. No centro da imagem, temos o núcleo Educação Infantil que se ramifica para os outros dois: Educação Física e Criança.

O núcleo capitaneado pela palavra Educação Infantil se liga a palavras/termos, como prático, experiência, município, rede municipal, São Paulo, Vitória, CMEI, inclusão, professor, formação continuada, avaliação, diálogo, lúdico, gênero, instituição, trabalho pedagógico, concepção, movimento e brincar. Com exceção de município-professor-São Paulo e VitóriaCMEI, as demais palavras se encontram "soltas", sem ligação entre si.

Esse núcleo denota que a Educação Infantil está relacionada com as experiências que ocorrem nos municípios (ente federativo responsável pela oferta da primeira etapa da Educação Básica) e que abordam diversas temáticas, como questóes de gênero, processos avaliativos, formação docente e concepçóes sobre o movimento e o brincar. Todas essas temáticas permeiam a constituição da Educação Infantil como etapa formal de ensino e dos processos pedagógicos subjacentes a ela. Destacamos que Vitória e São Paulo estão entre as palavras de maior destaque devido fato de uma grande quantidade de publicações narrar as experiências ocorridas nessas Capitais. O núcleo Educação Física já produz outras conexões, nas quais aparecem as palavras: interdisciplinaridade, saber, experiência, reflexão, implicação, intervenção, aula, Educação Física escolar e cotidiano de forma dispersa. As palavras brincar, físico, infância, corpo, desenvolvimento, por sua vez, demonstram ligaçôes internas entre si. 
FIGURA 3 - Similitudes das palavras presentes nos títulos das produções acadêmico-científicas.

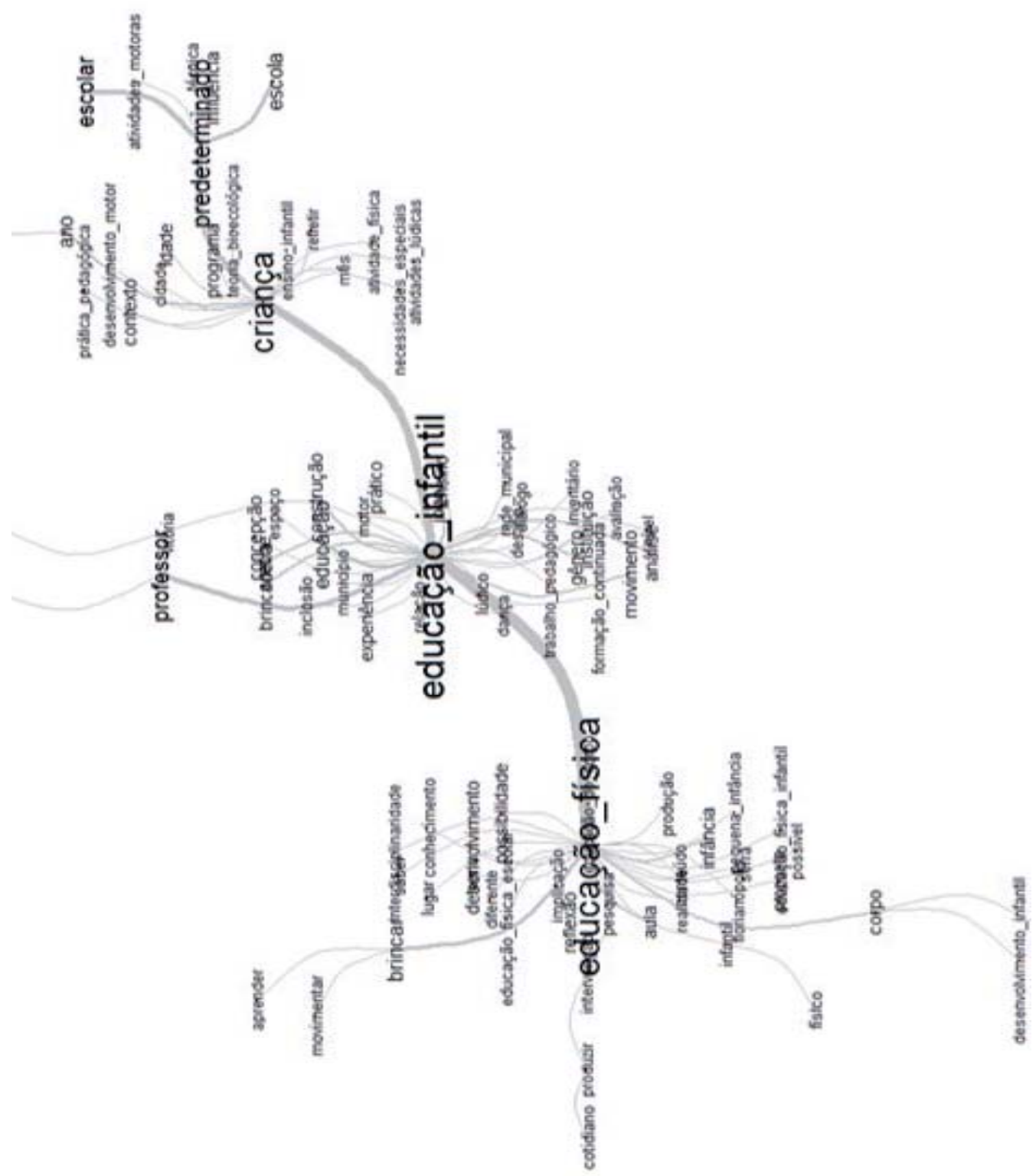

Fonte: Os autores

Da palavra brincar, temos uma bifurcação para movimentar e aprender. A palavra infantil está conectada a físico e o termo corpo está associado a desenvolvimento infantil. Dessa forma, pode indicar uma ideia de corpo (infantil) ligada à noção de desenvolvimento (físico), e de brincar associada à aprendizagem e ao movimento.

Nesse caso, a Educação Física, na primeira etapa da Educação Básica pode ser entendida como um componente curricular responsável por potencializar o aspecto motor das crianças. Desenvolver a motricidade infantil é de grande importância, pois possibilita o (re) conhecimento do próprio corpo, permite a execuçáo de diversas tarefas que conferem maior autonomia ao indivíduo e favorece processos de interações entre pares, especialmente quando realizados por meio da ludicidade, dos jogos e brincadeiras. Entretanto, é preciso atenção para não restringir os processos pedagógicos da Educação Física na Educaçâo Infantil apenas ao desenvolvimento físico-motor e transformar 
os jogos/brincadeiras em meros elementos de conduçâo a essa finalidade.

Segundo a $\mathrm{BNCC}^{10}$, o corpo e o movimento integram um dos campos de experiência a ser desenvolvido na Educação Infantil com a finalidade de construçáo de conhecimento e de produção cultural, o que possibilita às crianças vivenciam processos de socialização e de construção identitária. Os jogos/ brincadeiras na Educaçáo Infantil são entendidos pela BNCC como um direito de aprendizagem e não mais como um meio para outras aquisiçōes Mello, ZANDOMinegue, BARbosa, et al. ${ }^{15}$.

O núcleo Criança agrega palavras como desenvolvimento motor, atividades motoras, atividade física, programa, técnica, teoria bioecológica, idade, ano, mês, contexto, ensino infantil, prática pedagógica, estudo, refletir, necessidades especiais, atividades lúdicas. Chama a atenção o fato de termos uma ramificação direta da palavra "criança" com "predeterminado" que, por sua vez, se desdobra em influência, técnica, atividades motoras, escolar e escola. A própria presença do termo "teoria bioecológica" é sintomática para dizermos que a criança está sendo concebida como um sujeito universal, pautada por processos maturacionais de regulação endógena do organismo, pelos quais esses aspectos se estabelecem como preocupação final dos processos pedagógicos. Essa perspectiva exerce forte influência na Educaçáo Física escolar historicamente. Abordagens pedagógicas, como a Desenvolvimentista ${ }^{24}$, defendem que a Educaçáo Física escolar seja baseada em atividades que visem ao pleno desenvolvimento motor dos alunos, propondo, inclusive, uma taxonomia que estabeleça os movimentos que as crianças são capazes de realizar e precisam ser trabalhados em função da idade e da série escolar.

Os documentos pedagógicos orientadores das práticas pedagógicas da Educação Infantil apontam em sentido contrário a essa perspectiva, enfatizando que as crianças, mais do que um corpo físico a ser desenvolvido, devem ser assumidas como sujeitos históricos e de direito, capazes de construir sentidos sobre a natureza e a sociedade, produzindo cultura9. Ao analisarem a $\mathrm{BNCC}^{10}$ e as DCNEIs ${ }^{9}$, Mello, ZANDOMINEgUe, BARBosA, et al. ${ }^{15}$ afirmam que ambas avançam "[...] à noçáo de corpo e de movimento como forma de expressão e de produção de sentidos, inscritas num contexto cultural e distantes de uma ideia estereotipada e biologicista" (p. 144).

Para ter mais elementos que sustentem nossas análises, avaliamos os referenciais teóricos utilizados em todas as 218 produçóes acadêmico-científicas que compóem nossa amostra. Foram identificados 157 diferentes referenciais, sistematizados na FIGURA 4.

O critério utilizado para compor a FIGURA 4 foi que cada referencial teórico precisava ter sido utilizado como base em pelo menos três publicaçôes, independente se tese/dissertação, artigo científico ou trabalho acadêmico. Consideramos que o impacto da participação desses referenciais não pode ser examinado de forma isolada, mas, sim, pela conjunçáo deles em campos do conhecimento que os aglutinam sob uma mesma perspectiva teórica, conforme disposto no QUADRO 1.

O QUADRO 1 demonstra a influência massiva dos campos da Psicologia e do Comportamento Motor nas produçóes acadêmico-científicas sobre Educação Física na Educação Infantil. A liderança da Psicologia pode ser acrescida de outros autores que foram classificados nos campos da Educaçáo Física, Pedagogia e Documentos orientadores, isso porque esses campos estâo permeados por autores cujas obras são lastreadas em perspectivas teóricas típicas. É o caso de JB Freire (Psicologia piagetiana), RCNEI (Psicologia do desenvolvimento), Kishimoto (Psicologia do desenvolvimento).

A influência do Comportamento motor, que já foi destacada neste texto quando analisamos os títulos das produçóes em tela, está assentada em autores como Tani e Fonseca, signatários de uma abordagem pedagógica para a Educaçáo Física escolar denominada Desenvolvimentista ${ }^{24, \mathrm{~h}}$. Também é formada pela presença de Connolly, Ozmun e Gallahue, autores internacionais que defendem uma perspectiva de intervenção centrada no desenvolvimento de habilidades motoras por faixas etárias. Bronfenbrenner está associado à teoria bioecológica (muito recorrente, conectada à palavra criança nos títulos das publicaçóes). Sua teoria pressupóe a existência de níveis estruturais de desenvolvimento que se organizam em microssistema, mesossistema, exossistema e macrossistema que, como em efeito cascata ${ }^{\mathrm{i}}$, se interpóem ${ }^{25}$.

A presença e a influência da Psicologia também se faz na Educação Física, especialmente pela abordagem Construtivista $^{26}$ desenvolvida por Joáo Batista Freire que, entre outras questóes, defende o jogo e a brincadeira como meios para aquisição de determinadas habilidades e não como fim em si mesmo, como direito social, conforme preconizado pelas DCNEIs ${ }^{9}$ e pela $\mathrm{BNCC}^{10}$. Essa noção de jogo/brincadeira, concebidos com caráter instrumental pelo qual a função motora é privilegiada, similarmente é encontrada com essa mesma característica no RCNEI ${ }^{8}$.

O brincar e jogar também são dimensões recorrentes nas produçóes assinadas por Kishimoto. A referida autora trabalha com o conceito de "jogo 
FIGURA 4 - Referenciais mais utilizados em artigos científicos, trabalhos acadêmicos e teses/ dissertações.

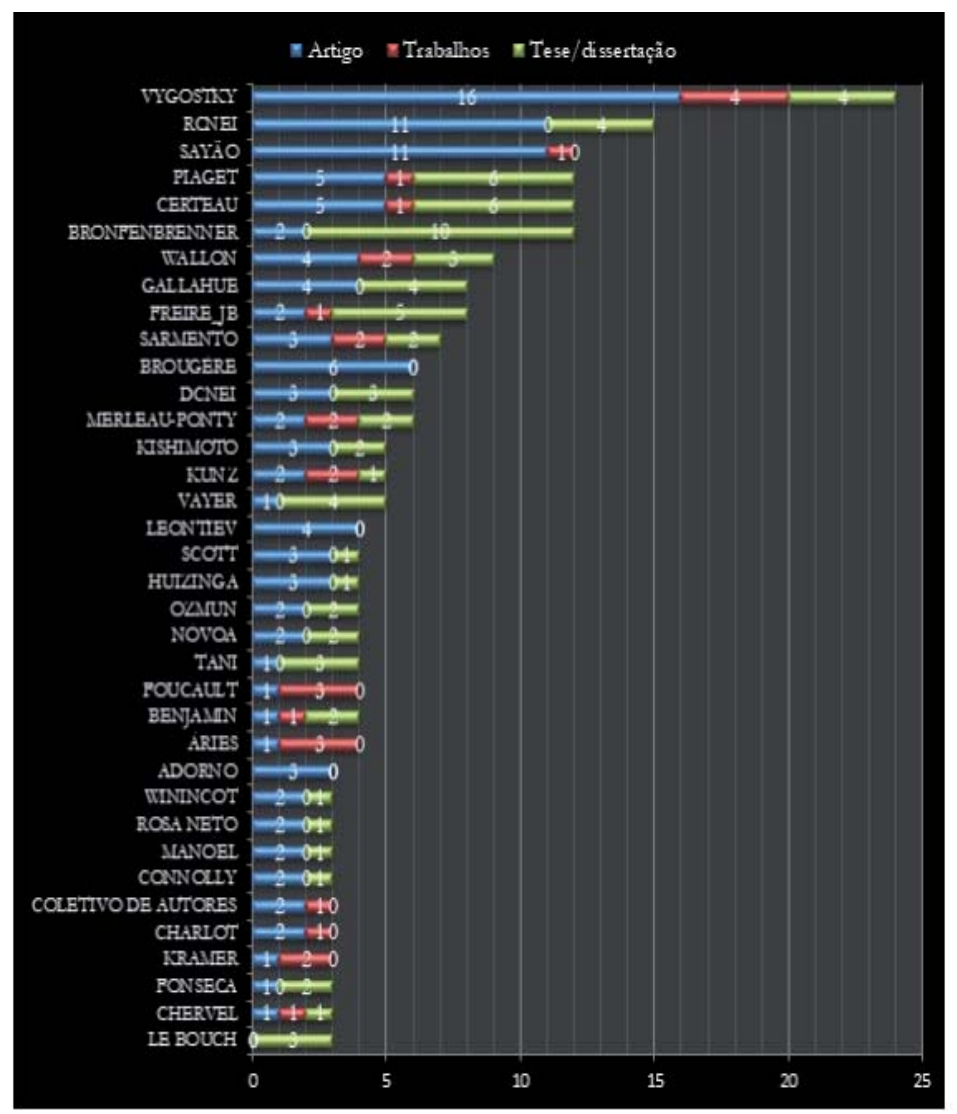

didático", no qual o ato de jogar se torna um eixo que conduz a um conteúdo didático específico, resultando em um empréstimo da ação lúdica para a aquisição de informações consideradas relevantes ao modelo escolar estabelecido ${ }^{15}$.

As DCNEIs ${ }^{9}$ e a BNCC $^{10}$ têm em comum o fato de defenderem que o trabalho pedagógico com o corpo e o movimento está para além da dimensão biológica funcionalista, assumindo uma perspectiva sociocultural que privilegia a produção de sentidos. As DCNEIs ${ }^{9}$ demarcam que a importância do corpo/ movimento está em ampliar o repertório cultural das crianças e os conhecimentos "[...] expressivos, corporais, que possibilitem movimentação ampla, expressão da individualidade e respeito pelos ritmos e desejos das crianças" (p. 99). A BNCC ${ }^{10}$ estabelece que um dos "campos de experiência"j a serem trabalhados com as crianças da Educação Infantil é o "Corpo, Gestos e Movimento". Nesse campo de experiência, o corpo é essencial na construção de sentido: “[...] por meio do tato, do gesto, do deslocamento, do jogo, da marcha, dos saltos, as crianças expressam-se, reconhecem sensaçóes, brincam, habitam espaços e neles se localizam, construindo conhecimento de si e do mundo" (p. 23).

Mello, Zandominegue, Barbosa, et al. ${ }^{15}$ compreendem, com base nesses documentos, que a importância atribuída ao corpo e ao movimento na Educação Infantil está relacionada com a produção cultural infantil e com os processos de autoria de suas práticas corpóreas. Nesse mesmo sentido, Nunes e Ferreira $\mathrm{NetO}^{27}$ advogam pela valorização do trabalho pedagógico com o movimento em sua totalidade, superando a visão restritiva de aquisição das habilidades motoras.

Não obstante a predominância de referenciais da Psicologia e do Comportamento motor, percebemos, na QUADRO 1, alguns autores que apontam em sentido contrário a esses postulados. O Coletivo de Autores defende uma mediação da Educação Física 
com base no materialismo histórico-dialético, em que as práticas pedagógicas têm como objetivo a captação da realidade que cerca a criança e da construção da sua identidade como sujeito social. Sayão problematiza a presença da Educação Física na Educação Infantil, ressaltando a necessidade de se compreender as singularidades do sujeito criança e do movimento corporal infantil como instrumento de apropriação das diferentes linguagens produzidas pela cultura, que é reinventada permanentemente pelas crianças. Sarmento e Certeau são muito presentes em publicaçóes que consideram as crianças protagonistas de seus processos de socialização e que, de forma ativa, produzem cultura entre pares.

Esse grupo de autores, utilizado como referenciais teóricos para embasar as discussóes propostas nas publicações analisadas, ao mesmo tempo em que se configura como um contraponto às influências da Psicologia e do Comportamento motor, em certa medida, possui proximidade com as concepçóes e pressupostos presentes nos documentos orientadores da Educação Infantil.

QUADRO 1 - Campos do conhecimento, referenciais teóricos e quantidade de publicações.

\begin{tabular}{|c|c|c|}
\hline Campo do conhecimento & Referencial teórico & Quantidade \\
\hline Comportamento Motor & $\begin{array}{l}\text { Tani (4) } \\
\text { Gallahue (8) } \\
\text { Ozmun (4) } \\
\text { Bronfenbrenner (12) } \\
\text { Manoel (3) } \\
\text { Connolly (3) } \\
\text { Rosa Neto (3) } \\
\text { Fonseca (3) }\end{array}$ & 40 \\
\hline Psicologia & $\begin{array}{l}\text { Vygotsky (24) } \\
\text { Leontiev (4) } \\
\text { Piaget (12) } \\
\text { Wallon (9) } \\
\text { Vayer (5) } \\
\text { Le Boulch (3) } \\
\text { Winnincot (3) }\end{array}$ & 60 \\
\hline Sociologia & $\begin{array}{l}\text { Sarmento (7) } \\
\text { Charlot (3) } \\
\text { Chervel (3) } \\
\text { Scott (4) }\end{array}$ & 17 \\
\hline Filosofia & $\begin{array}{l}\text { Merleaut-Ponty (6) } \\
\text { Foucault (4) } \\
\text { Adorno (3) } \\
\text { Benjamin (4) }\end{array}$ & 17 \\
\hline Educação Física & $\begin{array}{l}\text { Sayão (12) } \\
\text { Coletivo de Autores (3) } \\
\text { Kunz (5) } \\
\text { Jóao Batista Freire (8) }\end{array}$ & 28 \\
\hline Documentos Orientadores & $\begin{array}{l}\text { DCNEI (6) } \\
\text { RCNEI (15) }\end{array}$ & 21 \\
\hline Formaçāo Docente & Nóvoa (4) & 4 \\
\hline Pedagogia & $\begin{array}{l}\text { Kishimoto (5) } \\
\text { Kramer (3) }\end{array}$ & 8 \\
\hline História & $\begin{array}{l}\text { Àries (4) } \\
\text { Certeau (12) }\end{array}$ & 16 \\
\hline Jogos/Brincadeiras & $\begin{array}{l}\text { Huizinga (4) } \\
\text { Brougère (6) }\end{array}$ & 10 \\
\hline
\end{tabular}

76 • Rev Bras Educ Fís Esporte, (São Paulo) 2021J an-Mar;35(1):67-79 


\section{Discussão}

Os dados apurados mostram que a produção acadêmico-científica sobre Educação Infantil nos veículos de comunicação científica da Educação Física cresceu nas últimas décadas com uma média de 5,7 publicações.

Em uma análise mais qualitativa, percebemos que, nessas produçóes, predominam concepçóes biologicistas de Educação Física infantil e de criança sob forte influência de referenciais teóricos provenientes do campo da Psicologia e do Comportamento Motor, divergindo, assim, do que preconizam os documentos pedagógicos que orientam a Educação Infantil nacional ${ }^{9-10}$. Contudo, ainda que timidamente, também percebemos a presença de autores (referenciais) que estáo mais alinhados das concepçóes que fundamentam as $\mathrm{DCNEIs}^{9}$ e a $\mathrm{BNCC}^{10}$. A presença de referenciais provenientes da Filosofia e da Sociologia e de autores, como Sayão e Certeau, é sintomática nessa direção.

Diante desse cenário, torna-se pertinente indagar se esse fato não póe em risco a presença (ou ampliação) de professores com formação específica em Educação Física na primeira etapa da Educação Básica. Isso porque, na medida em que tais documentos se constituem como balizadores da organizaçáo e dos processos de ensino-aprendizagem da Educação Infantil, concepçôes destoantes dos pressupostos que o fundamentam, podem "depor contra" a presença/permanência desses professores nessa etapa de ensino.

É importante ponderar que essas análises são decorrentes de um recorte que, a partir dos critérios estabelecidos, focalizou a produção acadêmicocientífica em determinados veículos e determinada área do conhecimento, não nos permitindo afirmar que representam a totalidade do que circula no meio acadêmico. Para tanto, teríamos que ampliar esse exame para a área da educação (nos seus congressos, nos seus programas de pós e nas suas revistas específicas).

\section{Notas}

a Modificada posteriormente, em 2006, para zero a cinco anos de idade, devido à Lei no 11.274 , que transforma o Ensino Fundamental em nove anos.

b. Principal periódico do início do século XX, juntamente com a Revista Educação Physica.

c. Estudo que aborda apenas um setor das publicaçóes sobre o tema estudado.

d. Disponível em: http://bancodeteses.capes.gov.br/banco-teses/\#!/.

e. Cabe ressaltar que, atualmente, não há nenhum periódico nacional que publica pesquisas relacionadas com as subáreas sociocultural e pedagógica da Educação Física, classificados como A1.

f. O Grupo de Trabalho Temático (GTT) "Escola” foi a nossa referência de busca, entendendo que, nesse GTT, circulam as publicaçóes que tematizam a presença da Educação Física nas diversas etapas da Educação Básica.

g. Dentre as ferramentas disponíveis nesse software, utilizamos a nuvem de palavras, que agrupa as palavras e as organiza em função de sua frequência; e a análise de similitudes, que permite identificar as coocorrências entre as palavras e a conexidade que há entre elas.

h. Explicada anteriormente de forma sucinta.

i. Alguns autores fazem analogia às cascas de uma cebola em que uma estrutura está dentro da outra.

j. Modo organizativo adotado pela BNCC para identificar os conhecimentos/saberes a serem desenvolvidos com as crianças de zero a cinco anos de idade.

\section{Agradecimentos}

Ao Conselho Nacional de Desenvolvimento Científico e Tecnológico pela concessão de bolsa de iniciação à pesquisa.

\section{Conflito de interesse}

Não há conflito de interesse. 


\section{Abstract \\ Critical review of the Brazilian literature about sports news coverings of women's soccer}

This article analyzes the academic-scientific productions of Physical Education on Early Childhood Education, in dialogue with the concepts and assumptions present in the current guiding documents of this segment of education in Brazil. It makes a State of the Art about these publications, seeking to subsume and systematize the production in this area of knowledge. It is a bibliographical research that uses as sources: 76 theses and dissertations defended in the Graduation Programs in Physical Education of Brazil, 117 articles published in scientific journals of the area and 25 academic papers published in Annals of the Brazilian Congress of Sports Sciences. It adopts the Iramuteq software for analysis of the textual corpus. It is noticed that, although timidly, there are theoretical references that are more aligned with the perspective of childhood present in the guidance documents of the Infantile Education in the Country. Biologicist concepts of Physical Education infantile and of child under strong influence of theoretical references coming from the field of Psychology and Motor Behavior predominate in the investigated productions, thus diverging from those stated in the mentioned documents.

KEYWORDS: Publications; State of art; Official guiding documents; Childhood.

\section{Referências}

1. Kuhlmann Junior M. História da Educação Brasileira. Rev Bras Educ. 2000;14:5-19.

2. Brasil. Lei no 8.069, de 13 de junho de 1990. Estatuto da Criança e do Adolescente. [citado 10 dez 2017]. Disponível em: http://www.planalto.gov.br/Ccivil_03/leis/L8069.htm.

3. Rossetti-Ferreira MCR, Mello AM, Vitória T, Chaguri AC, organizadores. Os fazeres na educação infantil. São Paulo: Cortez; 2000.

4. Brasil. Lei no 9394, de 20 de dezembro de 1996. Lei de Diretrizes e Bases da Educaçáo Nacional. [citado em 10 jan 2018]. Disponível em: http://www2.senado.leg.br/bdsf/bitstream/handle/id/529732/lei_de_diretrizes_e_bases_1ed. pdf.

5. Paschoal JD, Machado MCG. A história da educação infantil no Brasil: avanços, retrocessos e desafios dessa modalidade educacional. HISTEDBR. 2009;33:78-95.

6. Martins RLD. O Pibid e a formação docente em educação física para a educação infantil. [dissertação] Vitória (ES): Universidade Federal do Espírito Santo, Centro de Educaçáo Física e Desportos; 2015.

7. Brasil, Lei no 13.005, de 25 de junho de 2014. Institui o Plano Nacional de Educação. [citado 10 jan 2018]. Disponível em: http://www.observatoriodopne.org.br/uploads/reference/file/439/documento-referencia.pdf.

8. Brasil. Secretaria de Educação Infantil. Referencial curricular nacional para a educação infantil. Brasília: Ministério da Educação; 1998.

9. Brasil. Secretaria de Educação Básica. Revisão das Diretrizes Curriculares Nacionais para a Educação Infantil. In: Brasil. Diretrizes Curriculares Nacionais Gerais da Educação Básica. Brasília: DICEI; 2013. p. 80-101.

10. Brasil. Ministério da Educação. Base Nacional Comum Curricular. Terceira versão revista. [citado em 15 dez 2017]. Disponível em: http://basenacionalcomum.mec.gov.br/.

11. Sirota R. Emergência de uma nova sociologia da infância: evolução do objeto e do olhar. Cad Pesq. 2001;112:7-31.

12. Corsaro W. Reprodução interpretativa e cultura de pares. In: Muller F, Carvalho AMA, organizadores. Teoria e prática na pesquisa com crianças: diálogos com William Corsaro. São Paulo: Cortez; 2009. p. 31-50.

13. Sarmento, M. J. A sociologia da infância e a sociedade contemporânea: desafios conceituais e praxeológicos. In: Ens RT; Garanhani MC, organizadores. Sociologia da infância e a formação de professores. Curitiba: Champagnat; 2013. p. $13-46$.

14. Silva CF, Raitz, TR, Ferreira VS. Desafios da sociologia da infância: uma área emergente. Psicol Soc. 2009;21(1):75-80.

15. Mello AS, Zandomínegue BAC, Barbosa RFM, et al. A Educação infantil na Base Nacional Comum Curricular: pressupostos e interfaces com a Educação Física. Motrivivência. 2016;28(48):130-149.

78 • Rev Bras Educ Fís Esporte, (São Paulo) 2021J an-Mar;35(1):67-79 
16. Mello AS, Nascimento ACS, Bissoli, FB, Santos, ML. Educação física na educação infantil: um estudo em periódicos da área. In: Mello AS, Santos W, organizadores. Educação física na educação infantil: práticas pedagógicas no cotidiano escolar. Curitiba: Editora CRV; 2012. p. 41-56.

17. Moura DL, Costa KRN, Antunes MM. Educação física e educação infantil: uma análise em seis periódicos nacionais. Pensar Prát. 2016;19(1):182-195.

18. Picelli LA. Produção científica sobre educação infantil nos Programas de Pós-Graduação em Educação Física no Brasil. [Dissertação] Uberlândia (MG): Universidade Federal de Uberlândia, Faculdade de Educação; 2002.

19. Bezerra FM. Educação física no jardim de infância: concepçóes e práticas corporais na Revista de Educação Física do Exército (1932-1942). [dissertação] Recife (PE): Universidade Federal de Pernambuco, Centro de Educação; 2011.

20. Romanowski JP, Ens RT. As pesquisas denominadas do tipo "Estado da Arte” em educação. Diálogos Educ. 2006;6(19):37-50.

21. Ferreira NSA. As pesquisas denominadas “Estado da Arte”. Educ Soc. 2002;79:257-272.

22. Lima TCS, Mioto RCT. Procedimentos metodológicos na construção do conhecimento científico: a pesquisa bibliográfica. Katálysis. 2007;10:37-45.

23. Camargo B, Justo AM. Tutorial para uso do software de análise textual Iramuteq. Florianópolis: Laccos; 2013.

24. Tani G, Manoel EJ, Kokubun E, Proença JE. Educação física escolar: fundamentos de uma abordagem desenvolvimentista. São Paulo: Edusp; 1988.

25. Spessato BC, Valetina NC, Krebs RJ, Berleze A. Educação infantil e intervenção motora: um olhar a partir da teoria bioecológica de Bronfenbrenner. Movimento. 2009;15(4):147-173.

26. Freire JB. Educação de Corpo Inteiro: teoria e prática da Educação Física. São Paulo: Scipione; 2009.

27. Nunes KR, Ferreira Neto A. Saberes e fazeres praticados nos cotidianos da educação física na educação infantil. Pensar Prát. 2011;14(1):1-10.

\begin{tabular}{r|l} 
ENDEREÇO & \\
Rodrigo Lema Del Rio Martins & Submetido: 06/04/2018 \\
BR 465, KM 7 & Revisado: 31/07/2018 \\
Praia de Itaparica & Aceito: 12/ 10/2018 \\
23897-000 - Seropédica - RJ - Brasil & \\
E-mail: rodrigodrmartins@ufrrj.br & \\
&
\end{tabular}

